\title{
Is Administration of Gadolinium-Based Contrast Media to Pregnant Women and Small Children Justified?
}

CME

\author{
Pia C. Sundgren, $\mathrm{MD}, \mathrm{PhD}^{1,2 *}$ and Peter Leander, $\mathrm{MD}, \mathrm{PhD}^{3}$
}

This article is accredited as a journal-based CME acitivity. If you wish to receive credit for this activity, please refer to the website: www.wileyblackwellcme.com

\section{ACCREDITATION AND DESIGNATION STATEMENT}

Blackwell Futura Media Services designates this journalbased CME activity for a maximum of 1 AMA PRA Category 1 Credit $^{\mathrm{TM}}$. Physicians should only claim credit commensurate with the extent of their participation in the activity.

Blackwell Futura Media Services is accredited by the Accreditation Council for Continuing Medical Education to provide continuing medical education for physicians.

\section{EDUCATIONAL OBJECTIVES}

Upon completion of this educational activity, participants will be better able to discuss the use of gadolinium-based contrast media in pregnant or lactating women and small children.

\section{ACTIVITY DISCLOSURES}

No commercial support has been accepted related to the development or publication of this activity.

Faculty Disclosures:

The following contributors have no conflicts of interest to disclose:

Editor-in-Chief: C. Leon Partain, $\mathrm{MD}, \mathrm{PhD}$

CME Editor: Scott B. Reeder, MD, PhD

CME Committee: Scott Nagle, MD, PhD, Pratik Mukherjee, MD, PhD, Shreyas Vasanawala, MD, PhD, Bonnie Joe, $\mathrm{MD}, \mathrm{PhD}$, Tim Leiner, MD, PhD, Sabine Weckbach, MD, Frank Korosec, PhD

Authors: Pia C. Sundgren, MD, PhD, Peter Leander, PhD

This manuscript underwent peer review in line with the standards of editorial integrity and publication ethics maintained by Journal of Magnetic Resonance Imaging. The peer reviewers have no relevant financial relationships. The peer review process for Journal of Magnetic Resonance Imaging is double-blinded. As such, the identities of the reviewers are not disclosed in line with the standard accepted practices of medical journal peer review.

Conflicts of interest have been identified and resolved in accordance with Blackwell Futura Media Services's Policy on Activity Disclosure and Conflict of Interest. No relevant financial relationships exist for any individual in control of the content and therefore there were no conflicts to resolve.

\section{INSTRUCTIONS ON RECEIVING CREDIT}

For information on applicability and acceptance of CME credit for this activity, please consult your professional licensing board.

This activity is designed to be completed within an hour; physicians should claim only those credits that reflect the time actually spent in the activity. To successfully earn credit, participants must complete the activity during the valid credit period, which is up to two years from initial publication.

Follow these steps to earn credit:

- Log on to www.wileyblackwellcme.com

- Read the target audience, educational objectives, and activity disclosures.

- Read the article in print or online format.

- Reflect on the article.

- Access the CME Exam, and choose the best answer to each question.

- Complete the required evaluation component of the activity.

This activity will be available for CME credit for twelve months following its publication date. At that time, it will be reviewed and potentially updated and extended for an additional twelve months.

\footnotetext{
${ }^{1}$ Centre for Medical Imaging and Physiology, Skåne University Hospital, Lund University, Lund, Sweden.

${ }^{2}$ Department of Radiology, University of Michigan Health Systems, Ann Arbor, Michigan, USA.

${ }^{3}$ Diagnostic Centre, Skåne University Hospital, Lund University, Malmö, Sweden.

*Address reprint requests to: P.C.M.S., Professor of Radiology, Centre for Medical Imaging and Physiology, Skåne University Hospital, Lund University, SE.221 85 Lund, Sweden. E-mail: pia.sundgren@med.lu.se

Received January 29, 2010; Accepted October 5, 2010.

DOI $10.1002 /$ jmri.22413

View this article online at wileyonlinelibrary.com.
} 
The use of gadolinium-based contrast media in pregnant or lactating women has been discouraged at many radiology departments due to the lack of knowledge of the risks for the fetus and the unwillingness to expose neonates to unnecessary drugs. In the present review the current literature and present guidelines regarding the use of gadolinium-based contrast media have been reviewed to validate the justification for their administration to pregnant or lactating women and small children.

Key Words: MR; gadolinium; pregnant women; children J. Magn. Reson. Imaging 2011;34:750-757.

(c) 2011 Wiley-Liss, Inc.

TODAY IT IS GENERALLY ACCEPTED that magnetic resonance imaging (MRI) can be performed in pregnant women if considered necessary. According to the American College of Radiology's 2007 White Paper for safe MR practices, MRI may be used in pregnant women if considered necessary by referring physicians and attending radiologists, irrespective of gestational age (1). The patient can be informed that, to date, there are no known harmful effects from the use of clinical MRI at $1.5 \mathrm{~T}$ or lower magnetic field strengths (2). As there is lack of experience with the use of field strengths greater than $2.5 \mathrm{~T}$ in pregnant women, the use of higher field strength than $1.5 \mathrm{~T}$ should be avoided in pregnant women at present (3). In addition, when it is clinically indicated to perform MR in a pregnant woman due to her illness (not for fetal MR), it is recommended that written informed consent be obtained to document the patients' understanding of the risk-benefit ratio and if alternative diagnostic options are available to answer the clinical question at hand (1).

When examinations using MRI are considered during pregnancy they are often performed without gadolinium-enhanced images due to the concern for potential harmful effects of the contrast medium to the fetus.

The decision to administer contrast media for MRI in pregnant women is controversial. Despite the lack of evidence of any harmful effects, the general rule within the radiological community is to avoid injection of contrast media to pregnant women out of general cautiousness. Asked for the primary reason not giving gadolinium-based contrast media to pregnant women in a recent small survey including 20 academic centers, the majority of centers reported the risk to the fetus as the major reason for avoiding contrast administration (4).

Gadolinium is classified as a category $\mathrm{C}$ drug by the U.S. Food and Drug Administration (FDA) and can be used if considered critical; in other words, it should be administered only if the potential benefits justify the potential risk to the fetus. Gadolinium is harmless in chelated form but severely toxic in its free form. Both animal and human studies have shown that gadolinium crosses the placenta, and is extracted by the fetal kidneys into the amniotic fluid (5-12). In this location, gadolinium chelate molecules remain for a relatively long period before finally being reabsorbed and eliminated. The longer the chelate molecule remains in this space, the greater the potential for dissociation of gadolinium ion from its chelate molecule (1). The recommendations in the recent 2007 American College of Radiology Guidance Document for safe MRI practices are that intravenous gadolinium should be avoided during pregnancy and should only be used if absolutely essential for the diagnosis (1).

There are barely any reports in the literature on the value of the indiscriminate use of intravenous contrast media administration in MRI of small children. A few recent studies, performed by one group, focused on the brain and spine and demonstrated that indiscriminate use of intravenous contrast media to neonates and infants (under the age of 2 years) neither helped in the diagnosis nor in detecting abnormalities (13-15). In other instances, such as certain studies of congenital heart disease and evaluation of abdominal disease, eg, neuro- and nephroblastoma contrast-enhanced examinations may be necessary and are judged justified.

The purpose of this article is to review the literature and existing guidelines to see if there is ever a justification to give nonspecific extracellular gadoliniumbased contrast media to pregnant women and what rules should apply if contrast is given to lactating women or to small children.

\section{ANIMAL STUDIES \\ Toxic Effects to Fetus}

Some previous animal studies with all of the by-now approved contrast media have shown potential fetal toxic effects with growth retardation and congenital anomalies. The effects have been observed when these media were administered at doses two to seven times higher than those used in humans and/or during extensive periods of exposure (16-21).

Other preclinical studies have not shown any potential negative effects on the fetus (22-26). In a study of 700 mice fetuses, investigating the results of exposure of pregnant mice to the combination of MRI and gadopentetate dimeglumine (Magnevist) at 9.5 days of gestation, the authors found no evidence of an increase in abortions, stillbirths, or grossly detectable eye, ear, facial, limb, or extremity defects (23). In another study by the same group no detectable chromosomal damages were demonstrated in 18 rats injected with 1.14$1.6 \mathrm{mmol} / \mathrm{kg}$ of gadopentetate dimeglumine, a dose that is more than 11-16 times the recommended clinical dose (26). There have been no long-term animal studies to evaluate the carcinogenic potential of gadoliniumbased contrast media. In animals exposed in utero to clinical dosages of gadolinium-based contrast media, no carcinogenic or mutagenic effects have been observed and no other long-term effects have occurred (22-26).

\section{Placental Transfer of Gadolinium-Based Contrast Media}

Gadolinium contrast media have been shown in the placenta following intravenous contrast administration to the mother in animals. In eight pregnant rabbits at third trimester the highest placental 
gadolinium concentration occurred 5 minutes after an injection of $0.1 \mathrm{mmol} / \mathrm{kg}$ of gadopentetate dimeglumine (Magnevist), with a 50\% decrease present at 60 minutes (9). The placental concentrations of gadolinium were initially high $(16.6 \pm 3.4 \mu \mathrm{g} / \mathrm{g})$ and then declined with a biexponential pattern. Initial gadolinium levels in the fetal organs were low and remained so except for the fetal kidneys, which showed increased levels of gadolinium from $4.3 \pm 1.1 \mu \mathrm{g} / \mathrm{g}$ at 5 minutes to $6.8 \pm 1.8 \mu \mathrm{g} / \mathrm{g}$ at 60 minutes. Similar findings have been seen in a study in pregnant rats (10). In that study $0.3 \mathrm{mmol} / \mathrm{kg}$ 14C-labeled gadodiamide (Omniscan) were injected to the rats on day 18 of gestation, with the highest placental concentration present at the end of the injection, equal to between 18\%-30\% of the injected dose. There was a decrease of about 100-fold by 24 hours, with the majority of the decrease occurring in the first 4 hours (10). Other animal models including a study of 22 pregnant BALB/c mice injected with double and quadruple the clinical dose have demonstrated contrast-enhanced MRI to be effective in the measurement of placental blood flow and rate of transfer of contrast material between the maternal and fetal circulation (11).

\section{HUMAN STUDIES}

\section{Toxic Effect to Fetus}

To date, no adequate, well-controlled studies in humans regarding the potential effects of in utero exposure to intravenous gadolinium-based contrast media have been performed.

\section{Placental Transfer of Gadolinium Contrast Media}

In one of the few clinical studies of placental imaging performed in 11 women between 16 and 37 weeks of pregnancy, gadolinium uptake into the placenta following a single dose of $0.1 \mathrm{mmol} / \mathrm{kg}$ body weight of gadopentetate dimeglumine (Magnevist) was enough for imaging of the placenta with no adverse effects noted (12).

It has been demonstrated that gadoliniumenhanced dynamic MRI can provide excellent contrast between the myometrium and placenta in a study of six pregnant women with prior cesarean section, examined at 34-38 gestational weeks (27).

Important, regarding placental imaging, as has been pointed out before, is that the indication to image usually arises after the 36th week of gestation, just prior to delivery, well beyond the period of organogenesis (28).

\section{Effects on Neonates After Gadolinium Administration in Pregnant Women}

There are few clinical reports of the effects on neonates after administration of gadolinium contrast media to the mother in the first trimester.

No adverse effects were seen in the neonates after intentional gadolinium administration in a limited study of two pregnant women with Crohn's disease during the first trimester (29), or in one case of inadvertent gadolinium exposure during the first trimester (30). In a more recent study of 26 pregnant women exposed to gadolinium-based contrast media in the first trimester, no adverse effects on pregnancy and neonatal outcome were seen (31).

Reports on the use of gadolinium-based contrast agents during the second or third trimester do exist underscoring the usefulness of these agents in diagnosing various conditions. No harm to the fetus and neonates has been documented in these reports $(12,27,32,33)$. A recent study using gadolinium in pregnant women, evaluating placenta accreta, demonstrated that contrast-enhanced MRI improves the diagnostic accuracy compared to nonenhanced, T2-weighted imaging (27). Three of the newborns in that study suffered from perinatal complications of fetal distress or meconium staining (27). Whether this was related to the MRI study is unknown but must, in our opinion, be considered less likely, as these studies were performed immediately prior to delivery and the exposure to the contrast agent was limited.

In a present study of 29 pregnant women with a mean gestational age of 27 weeks (ranging from 1331 weeks) with acute abdominal and pelvic pain, seven received contrast agent $(0.1 \mathrm{mmol} / \mathrm{kg}$ Omniscan) to aid in the diagnosis without any reported adverse events to the fetus (33). Also in a study evaluating the placenta in 11 pregnant women, no adverse effects and no abnormalities to the child were detected after birth (27). Symptomatic hydronephrosis has been studied in 11 women at 19-34 weeks of gestation, injected with $0.1 \mathrm{mmol} / \mathrm{kg}$ of gadopentetate dimeglumine (Magnevist) with no reported adverse effects to the neonates at delivery (34).

However, there are institutions that do not use gadolinium agents in pregnant women in their studies. In a recent review of the use of MRI in pregnant and nonpregnant women with acute right lower quadrant pain, no contrast media was given to the pregnant women (35). Contrast was neither given in another study evaluating the value of MRI in pregnant women with acute abdominal and pelvic pain (36) nor in an MRI study of acute appendicitis in pregnant women (37).

\section{Current Practice}

In a published survey from 183 radiology residency programs in the U.S., evaluating current practice patterns in the imaging of pregnant women with abdominal complaints $94 \%$ of the centers performed MRI in pregnant women but only 33\% gave intravenous gadolinium agents (38). The most common indication for the administration of gadolinium was malignancy staging. The majority of the centers preferred MRI over computed tomography (CT) for imaging of appendicitis and abscesses in the first trimester (39\% vs. $32 \%$ and $46 \%$ vs. $32 \%$ ), while in the second and third trimester most centers preferred CT (38). At the 2009 annual meeting of the ISMRM a small survey that evaluated the current practice from 18 academic centers in Europe, Asia, and the USA presented similar findings: $33 \%$ of them gave gadolinium to pregnant women, $67 \%$ gave gadolinium in all three trimesters, whereas $33 \%$ only in the third trimester (4). 
In summary, to our knowledge and supported by the limited reports in the literature, there have been no known adverse effects to human fetuses reported to date when clinically recommended dosages of gadolinium-based contrast media have been given to pregnant women. There are no studies supporting the use of one gadolinium-based contrast medium before the other to pregnant women. However, the Contrast Media Safety Committee of the European Society of Urogenital Radiology (39) recommends the use of the most stable agents, ie, macrocyclic agents.

\section{Risk of Gadolinium-Based Contrast Medium Administration During Lactation}

The recommendations regarding lactating women who receive intravascular gadolinium have been inconsistent over the course of time. Previously it was generally recommended to stop breastfeeding for 24 hours after gadolinium administration. The earlier guidelines from the Contrast Media Safety Committee of the European Society of Urogenital Radiology (v. 6.0) together with a published article (40) stated that breastfeeding could be continued. However, in the most recent version (7.0) it is stated that breastfeeding should be avoided 24 hours after gadolinium has been used (39). From a scientific point of view the rationale for lactating women to discontinue breastfeeding for 24 hours and to discard all milk expressed during this time is extremely weak. The recommended pediatric dose of gadolinium agents is $0.1-0.2 \mathrm{mmol} /$ $\mathrm{kg}$ and this dose is considered well tolerated in infants less than 6 months old (41-44). Several recent studies have shown that only a tiny amount of gadolinium-based contrast medium given to a lactating woman reaches her milk (45-47). A study of 20 lactating women given $0.1 \mathrm{mmol} / \mathrm{kg}$ gadopentetate dimeglumine (Magnevist) (19 of the 20 women) and $0.2 \mathrm{mmol} / \mathrm{kg}(1 / 20)$ showed that less than $0.04 \%$ of the total maternal dose of intravenous gadolinium passes into the breast milk, which means that the amount transferred to a nursing infant orally would be less than $1 \%$ of the permitted intravenous dose for neonates (44). Similar results have been observed in other studies of lactating women. In a lactating woman who received $0.1 \mathrm{mmol} / \mathrm{kg}$ of gadopentetate dimeglumine (Magnevist) the cumulative excreted dose of gadolinium was $0.011 \%$ of the total dose given (46) and in another study of a lactating woman given the same dose of gadopentetate dimeglumine the cumulative gadolinium excretion was $0.023 \%$ of the administrated dose over 24 hours (47).

The small fraction of the agent should be evaluated in conjunction with the small fraction taken up through the infant gut. Hence, only a very minute systemic dose to the infant will be the result after gadolinium administration to the mother (44).

Based on these facts we believe there is no reason to discontinue breastfeeding for 24 hours. This is in accord with several other authors $(45,48,49)$. The change in the guidelines from the Contrast Media Safety Committee of the European Society of Urogeni- tal Radiology may reflect the attention paid to nephrogenic systemic fibrosis (NSF) (see below).

\section{Gadolinium-Based Contrast Media Administration in Children}

The commonly used gadolinium-based contrast media, Magnevist, Ominscan, and MultiHance, have been proven safe also for children and are used in children under the age of 6 months (41-44), in children 6 months and older (50), and in children $>2$ years (51).

The reported frequencies of adverse events in the pediatric population from intravenously administrated gadolinium-based contrast media are rare $(52,53)$. In a recent retrospective study of 13,344 pediatric patients (younger than 19 years) the reported frequency of adverse events was $0.04 \%$, with the majority of the events being mild and no deaths occurred (52).

The practice to give contrast to children varies in different institutions depending on their routine. At some institutions all pediatric examinations are supervised by radiologists who decide in the course of the examination about the administration of gadolinium when appropriate, while other institutions use predefined routine protocols which often include routine gadolinium administration. In a survey from 20 academic centers by Sundgren (4), the majority of the centers (87\%) reported supervising all pediatric examinations. Images after contrast administration were included in the routine imaging protocol at almost half of the centers (47\%), but of those $87 \%$ reported that they decide at the time of the study if contrast agent should be given or not (4).

Supervising pediatric MR examinations may hamper effectiveness, as it may limit the examinations to regular work-hours. The major reasons to not supervise the individual examinations are: the use of routine protocols selected based on clinical information, the performance of the examinations at off-hours, and time efficiency (4). Overall, it does not seem that many institutions have changed their protocols for small children despite concern of risk of NSF. In the survey, 20\% reported that they have changed their imaging protocols for small children (4). The remaining have not changed because they had already restricted protocols. However, 7\% reported that they feel that contrast is administrated too often in children (4).

In a few recent publications by one group the indiscriminate use of gadolinium in neuroimaging has been discussed (13-15). The authors concluded that 1) there is no general need for gadolinium in MRI of the brain in children younger than 2 years of age, with clinical questions regarding seizures and developmental delay; and 2) that gadolinium-based contrast media administration should be reserved for those with suspected or known brain infection and malignancy $(13,14)$. In one study of $437 \mathrm{MRI}$ in children younger than 2 years of age with the clinical question of first-time seizures, the authors evaluated if contrast administration was useful. The contrast administration was rated as essential, helpful, or not helpful for each study. The authors concluded that administration of contrast medium was felt to be 
Table 1

Recommendations for the Most Relevant Use of Gadolinium-Based Contrast Media (GBCM) in Pregnant or Lactating Women and Small Children

\begin{tabular}{|c|c|c|c|c|}
\hline & Neuroimaging & $\begin{array}{l}\text { Cardiovascular } \\
\text { imaging }\end{array}$ & $\begin{array}{l}\text { Musculoskeletal } \\
\text { imaging }\end{array}$ & $\begin{array}{c}\text { Thoracic and } \\
\text { abdominal imaging }\end{array}$ \\
\hline Pregnant women & $\begin{array}{l}\text { Evaluation of malignant } \\
\text { disease, infection or } \\
\text { granulomatous disease }\end{array}$ & $\begin{array}{l}\text { Pulmonary embolism: } \\
\text { MRA may be an } \\
\text { alternative. } \\
\text { Some institutions } \\
\text { have protocols w/o } \\
\text { use of GBCM }\end{array}$ & $\begin{array}{l}\text { Most investigations } \\
\text { can be postponed } \\
\text { to a time-point } \\
\text { after delivery }\end{array}$ & $\begin{array}{l}\text { Evaluation of a) placental } \\
\text { disorders, eg, placenta } \\
\text { accreta, increta or previa, } \\
\text { b) abdominopelvic pain } \\
\text { if imaging w/o GBCM } \\
\text { is inconclusive }\end{array}$ \\
\hline Lactating women & No restrictions & No restrictions & No restrictions & No restrictions \\
\hline Neonatal period & $\begin{array}{l}\text { GBCM to neonates and } \\
\text { infants (under the age } \\
\text { of } 2 \text { years) often not } \\
\text { necessary for detecting } \\
\text { the majority of } \\
\text { abnormalities }\end{array}$ & $\begin{array}{l}\text { Certain studies } \\
\text { of congenital } \\
\text { heart disease. }\end{array}$ & No clear indications & $\begin{array}{l}\text { Evaluation of malignant } \\
\text { disease, eg, neuro- } \\
\text { and nephroblastoma }\end{array}$ \\
\hline $\begin{array}{r}\text { Infants }<1 \\
\text { year old }\end{array}$ & $\begin{array}{l}\text { GBCM to neonates and } \\
\text { infants (under the age } \\
\text { of } 2 \text { years) often not } \\
\text { necessary for detecting } \\
\text { of the majority of } \\
\text { abnormalities }\end{array}$ & $\begin{array}{l}\text { Certain studies } \\
\text { of congenital } \\
\text { heart disease. } \\
\text { Severe aggressive } \\
\text { vascular malformations } \\
\text { that cannot be } \\
\text { postponed until } \\
\text { later in life. }\end{array}$ & $\begin{array}{l}\text { Bone and soft-tissue } \\
\text { tumours. Congenital } \\
\text { abnormalities } \\
\text { Osteomyelitis }\end{array}$ & $\begin{array}{l}\text { Evaluation of malignant } \\
\text { disease, eg, neuro- } \\
\text { and nephroblastoma. } \\
\text { Indeterminate sex } \\
\text { investigations. }\end{array}$ \\
\hline Childhood & $\begin{array}{l}\text { Evaluation of malignant } \\
\text { disease, infection or } \\
\text { granulomatous disease }\end{array}$ & $\begin{array}{l}\text { Follow up of heart } \\
\text { reconstruction. } \\
\text { Vascular } \\
\text { malformations. }\end{array}$ & $\begin{array}{l}\text { Bone and soft-tissue } \\
\text { tumours. Congenital } \\
\text { abnormalities } \\
\text { Osteomyelitis }\end{array}$ & $\begin{array}{l}\text { Evaluation of malignant } \\
\text { disease, eg, neuro- } \\
\text { and nephroblastoma. } \\
\text { Indeterminate sex } \\
\text { investigations. Evaluation } \\
\text { of inflammatory } \\
\text { bowel disease }\end{array}$ \\
\hline
\end{tabular}

essential in formulating a diagnosis in a total of 8 (1.8\%) studies, all of which involved documented or highly suspected cases of infection. In an additional 26 cases (5.9\%), which included four cases of neoplasm, contrast was felt to be useful but not essential in reaching a diagnosis. Contrast was judged not helpful in making the diagnosis in the other 403 of the 437 studies (92.3\%) (13). The same investigators also reviewed the MRI of 107 children under the age of 2 years in whom developmental delay was the primary or secondary concern (14). They concluded that there were no cases in which the findings would have been missed without gadolinium administration in the children with developmental delay as the primary concern. In the 63 patients in whom developmental delay was a secondary concern, there were several cases (11\%) where contrast was helpful but not essential in reaching a radiologic diagnosis. The authors concluded that intravenous gadolinium has an extremely low yield in children under the age of 2 when developmental delay is the primary concern. In young children in whom developmental delay is a secondary concern, they advocated the use of gadolinium particularly when tumor or infection is clinically suspected (14). Similar ideas have previously also been suggested by others (54).

Similarly, the value of contrast administration was considered to be limited in MRI of the spine in children younger than 2 years of age (15). In a recent MRI study of the spine in 186 children under the age of 2 years we evaluated the value of contrast administration in the spine. The contrast administration was rated as essential, helpful, or not helpful for each study. In that study, contrast was judged to be essential for the diagnosis in 21 of the 186 children (11.3\%); however, 18 of the 21 patients had a known history of neoplasm (15, unpubl. data). The authors concluded that gadolinium should definitely be part of the imaging protocol in patients with known neoplasm (brain and spine) and in patients with known/suspected vascular malformations as well as in those with a concern for infection (15). If these guidelines are followed, the potential call-back rate for contrast-enhanced imaging would be quite low (13-15, unpubl. data).

The value of contrast is undisputed in situations like staging of and/or follow-up of malignancies, known or suspected infections, and inflammatory conditions in neuroimaging. The same account in other areas of radiology, eg, certain studies of congenital heart disease, bone and soft-tissue tumors, and abdominal conditions as suspected neuro- and nephroblastoma (Table 1).

The indiscriminate use of gadolinium adds unnecessary costs and time to the MR examination. Additional postcontrast sequences prolong the examination by approximately one-third. In children who need sedation, this results in extra time under conscious sedation or general anesthesia, and although the associated risks are small, complications such as oxygen 
desaturation, airway management issues, and oversedation have been reported (55). This has to be weighed against the risks associated with repeated anesthesia for postcontrast imaging in those cases when the primary exam is performed without contrast but reveals a lesion that needs characterization with gadolinium.

The use of MRI protocols that include routine administration of contrast media can be perceived as a "defensive" practice of medicine. However, the pressure from referring clinicians and even radiologists to obtain as much information as possible from the MRI study in children in anesthesia cannot be neglected; therefore, these patients are more likely to receive contrast. Also, MRI of small children constitutes a relatively small volume of MRI and it can be difficult to gain some reliable experience of the value of contrast media administration in smaller MRI centers which, therefore, may proceed with protocols routinely including gadolinium.

As the administration of contrast media in children, unlike that in adults, is associated with issues of prolonged sedation/anesthesia, it is therefore desirable that centers with large pediatric clientele evaluate and give guidelines for the use of contrast media in specific indications.

\section{Nephrogenic Systemic Fibrosis (NSF) in Pregnant Women and in Children}

$\mathrm{NSF}$, the clinical aspects of which have recently been presented in a special issue on NSF in this journal (56), is linked to the injection of gadolinium-based contrast media in patients with impaired renal function. Its frequency is very low, varying from negligible up to $2 \%-5 \%$ in selected high-risk clinical situations (57-62). The risk factors include patients with a glomerular filtration rate (GFR) below $30 \mathrm{~mL} / \mathrm{min}$ / $1.73 \mathrm{~m}^{2}$ body surface (chronic kidney disease [CKD] stages 4-5), high-dose gadolinium-based contrast medium administration, inflammatory conditions, postoperative state, and hyperphosphatemia. Most patients with NSF have a very low renal function, many being in endstage renal disease and on dialysis. Some reports indicate the risk of NSF in the group of renal function between $59-30 \mathrm{ml} / \mathrm{min} / 1.73 \mathrm{~m}^{2}$ body surface (CKD stage 3). Approximately 400-500 NSF patients have been reported at the time when $\approx 150$ million gadolinium injections were administered (63). The most commonly reported gadolinium agent associated with NSF, in relation to number of administered doses, is gadodiamide (Omniscan, GE Healthcare, St. Giles, UK) followed by gadoversetamide (Optimark, Covidien/Mallinckrodt, St. Louis, MO), and gadopentetate dimeglumine (Magnevist, Schering Pharma, Berlin, Germany) (64).

European and FDA guidelines for gadolinium use in risk groups differ.

In November of 2009 the European Medicines Agency (EMEA) released that they has adopted new recommendations to minimize risk of NSF with gadolinium-containing contrast agents in patients at risk of developing the condition. The Agency's Committee for Medicinal Products for Human Use (CHMP) classified the gadolinium-based agents into three groups: highest risk of NSF, intermediate risk of NSF, and lowest risk of NSF. This classification is also adopted by the Contrast Media Safety Committee of the European Society of Urogenital Radiology (39). EMEA has issued contraindications for high-risk gadoliniumcontaining agents in patients with severe kidney disease (with GFR $<30 \mathrm{~mL} / \mathrm{min}$ ), patients with scheduled or recently received liver transplant, but more important in this context, in newborn babies up to 4 weeks. The agents classified as "highest risk of NSF" are gadodiamide (Omniscan), gadopentetate dimeglumine (Magnevist), and gadoversetamide (Optimark). The other agents can be used in these patients with caution and the smallest possible dose. In addition, if a "high-risk agent" is used in breastfeeding mothers it is stated "as a precaution, breastfeeding should be discontinued for at least 24 hours after the patient has received a 'highrisk agent'." There is no full scientific evidence for grouping the agents in different risk classes and it is based on "the best of knowledge" taking both experimental and clinical studies into account.

FDA guidelines are general and there are announced black-box warnings for the use of all gadolinium agents in patients with acute and chronic severe renal insufficiency GFR $<30 \mathrm{~mL} / \mathrm{min} / 1.73 \mathrm{~m}^{2}$ ) or acute renal insufficiency of any severity due to hepatorenal syndrome or in the perioperative liver transplantation period $(65,66)$. The FDA has issued statements that suggest a careful use of gadolinium-based contrast agents, particularly in infants due to the physiological immature kidney in the first weeks of life.

To our knowledge, no cases are linked to pregnant women or have been reported in children under the age of 8 years (67-69). To date, a total of nine cases of NSF in children age 8-19 years have been reported, all with serious renal endstage disease $(67,68,70)$.

\section{LIMITATIONS}

The review does not cover organ-specific gadoliniumbased contrast media.

\section{CONCLUSIONS}

As the knowledge- both documentation and reportsof possible adverse effects of gadolinium-based contrast media on the fetus is very limited, it is still wise to limit the administration of gadolinium-based contrast media to pregnant women in situations when the added information is considered necessary/essential for further treatment.

There is no real reason to discontinue breastfeeding for 24 hours after the administration of gadoliniumbased contrast media.

With the increased awareness of the negative effects of ionizing radiation to infants and children, there is an advantage of using MRI over CT in children. However, the indiscriminate use of contrast media in small children should be avoided for reasons of both prolonged scan time and need for longer sedation, as well as limited experience in the safety of gadoliniumbased agents, especially in infants. 
NSF is not a specific problem in pregnant women and small children but the same restrictions with respect to reduced kidney function should apply to pregnant women and children as to other patients undergoing MRI. The physiologically immature kidney in early life should receive special attention.

\section{REFERENCES}

1. Kanal E, Barkovich AJ, Bell C, et al. ACR guidance document for safe MR practices: 2007. AJR Am J Roentgenol 2007; 188:1447-1474.

2. Shellock FG, Crues JV. MR procedures: biologic effects, safety, and patient care. Radiology 2004;232:635-652.

3. Wagner LK, Lester RG, Saldana LRExposure of the pregnant patient to diagnostic radiations: a guide to medical management, 2nd ed. Madison, WI: Medical Physics, 1997.

4. Sundgren PC. Is there a need for use of contrast in the pregnant mother and in small children. In: Proc 17th Annual Meeting ISMRM, Honolulu; 2009.

5. Shellock FG, Kanal E. Safety of magnetic resonance imaging contrast agents. J Magn Reson Imaging 1999;10:477-484.

6. Shellock FG, Kanal EBioeffects and safety of MR procedures. In: Edelman R, Heselink J, Zlatkin M, editors. Clinical magnetic resonance imaging. Philadelphia: Saunders; 1996:429.

7. American College of Radiology. Manual on contrast media, 5th ed. Reston, VA: American College of Radiology; 2004:44-45.

8. Jung SE, Byun JY, Lee JM, et al. MR imaging of maternal diseases in pregnancy. AJR Am J Roentgenol 2001;177:1293-1300.

9. Novak Z, Thurmond AS, Ross PL, Jones MK, Thornburg KL, Katzberg RW. Gadolinium-DTPA transplacental transfer and distribution in fetal tissue in rabbits. Invest Radiol 1993;28:828-830.

10. Okazaki O, Murayama N, Masubuchi N, Nomura H, Hakasui H. Placental transfer and milk secretion of gadodiamide injection in rats. Arzneimittelfors Drug Res 1996;46:83-86.

11. Taillieu F, Salomon LJ, Siauve N, et al. Placenta perfusion and permeability: simultaneous assessment with dual-echo contrast enhanced MR imaging in mice. Radiology 2006;241:737-745.

12. Marcos HB, Semelka RC, Worawattanakul S. Normal placenta: gadolinium-enhanced dynamic MR imaging. Radiology 1997;205: 493-496.

13. Petrou M, Foerster B, Maly PV, Eldevik PO, Leber S, Sundgren PC. Added utility of gadolinium in the MRI work-up of seizures in children under the age of two. J Child Neurol 2007;22:200-203.

14. Foerster BR, Ksar J, Petrou M, et al. Value of gadolinium administration in brain MRI examinations for developmental delay in children less than two years of age. Pediatr Neurol 2006;35: 126-130.

15. Jennings J, Petrou M, Sundgren PC, et al. The value of contrast administration in MRI of the spine in children under two years of age. In: Proc ECR 200, p 296, P4491.

16. Magnevist (brand of gadopentetate dimeglumine) injection [package insert]. Montville, NJ: Berlex; 2005.

17. Omniscan (gadodiamide) injection [package insert]. Waukesha, WI: General Electric Healthcare; 2002.

18. OptiMARK (gadoversetamide) injection [package insert]. St. Louis, MO: Mallinckrodt; 2003.

19. ProHance (gadoteridol) injection [package insert]. Princeton, NJ: BraccoDiagnostics; 2002.

20. MultiHance (gadobenate dimeglumine) injection [package insert]. Princeton, NJ: Bracco Diagnostics; 2005.

21. Panigel M, Wolf G, Zeleznick A. Magnetic resonance imaging of the placenta in rhesus monkeys, Macaca mulatta. J Med Primatol 1988;17:3-18.

22. Wible JH Jr, Galen KP, Wojdyla JK. Cardiovascular effects caused by rapid administration of gadoversetamide injection in anesthetized dogs. Invest Radiol 2001;36:292-298.

23. Rofsky NM, Pizzarello DJ, Weinreb JC, Ambrosino MM, Rosenberg C. Effect on fetal mouse development of exposure to MR imaging and gadopentetate dimeglumine. J Magn Reson Imaging 1994;4:805-807.

24. Soltys RA. Summary of preclinical safety evaluation of gadoteridol injection. Invest Radiol 1992;27(Suppl 1):S7-11.

25. Morisetti A, Bussi S, Tirone P, de Haen C. Toxicological safety evaluation of gadobenate dimeglumine $0.5 \mathrm{M}$ solution for injec- tion (MultiHance), a new magnetic resonance imaging contrast medium. J Comput Assist Tomogr 1999;23(Suppl 1):S207-217.

26. Rofsky NM, Pizzarello DJ, Duhaney MO, Falick AK, Prendengast $\mathrm{N}$, Weinreb JC. Effect on magnetic resonance exposure combined with gadopentetate dimeglumine on chromosomes in animal specimens. Acad Radiol 1995;2:492-496.

27. Tanaka Yo, Sohda S, Shigemitsu S, Niitsu M, Itai Y. High temporal resolution dynamic MRI in a high risk group for placenta accreta. Magn Reson Imaging 2001;19:635-642.

28. Palacios Jaraquemada JM, Bruno C. Gadolinium-enhanced MR imaging in the differential diagnosis of placenta accreta and placenta percreta [letter]. Radiology 2000;216:610-611.

29. Shoenut JP, Semelka RC, Silverman R, Yaffe CS, Micflikier AB. MRI in the diagnosis of Crohn's disease in two pregnant women. J Clin Gastroenterol 1993;17:244-247.

30. Barkhof F, Heijboer RJ, Algra PR. Inadvertent i.v. administration of gadopentetate dimeglumine during early pregnancy. AJR Am J Roentgenol 1992;158:1171.

31. De Santis M, Straface G, Cavaliere AF, Carducci B, Caruso A. Gadolinium preconceptional exposure: pregnancy and neonatal outcome. Acta Obstet Gynecol Scand 2007;86:99-101.

32. Leyendecker JR, Gorengaut V, Brown JJ. MR imaging of maternal diseases of the abdomen and pelvis during pregnancy and the immediate postpartum period. RadioGraphics 2004;24: 1301-1316.

33. Birchard KR, Broan MA, Hyslop WB, Firat Z, Semelka RC. MRI of acute abdominal and pelvic pain in pregnant patients. AJR Am J Roentgenol. 2005; 184:452-458.

34. Spencer JA, Tomlinson AJ, Weston MJ, Lloyd SN. Early report: comparison of breath-hold MR excretory urography, Doppler ultrasound and isotope renography in evaluation of symptomatic hydronephrosis in pregnancy. Clin Radiol 2000;55:446-453.

35. Pedrosa I, Zeikus EA, Levine D, Rofsky NM. MR imaging of acute right lower quadrant pain in pregnant and nonpregnant patients. RadioGraphics 2007;27:721-753.

36. Oto A, Ernst RD, Ghulmiyyah LM, et al. MR imaging in the triage of pregnant patients with acute abdominal and pelvic pain. Abdom Imaging 2009;34:243-250.

37. Pedrosa I, Levine D, Eyvazzadeh AD, Siewert B, Ngo L, Rofsky NM. MR imaging evaluation of acute appendicitis in pregnancy. Radiology 2006;238:891-899.

38. Jaffe, TA, Miller CM, Merkle EM. Practice patterns in imaging of the pregnant patient with abdominal pain: a survey of academic centers. AJR Am J Roentgenol 2007;189:1128-1134.

39. ESUR guidelines on contrast media. European Society of Urogenital Radiology, version 7.0. Available at: www.esur.org

40. Webb JA, Thomsen HS, Morcos SK; Members of Contrast Media Safety Committee of European Society of Urogenital Radiology (ESUR). The use of iodinated and gadolinium contrast media during pregnancy and lactation. Eur Radiol 2005;15:1234-1240.

41. Marti-Bonmati L, Vega T, Benito C, et al. Safety and efficacy of Omniscan (gadodimide injection) at $0.1 \mathrm{mmol} / \mathrm{kg}$ for MRI in infants younger than 6 months of age: phase III open multicenter study. Invest Radiol 2000;35:141-147.

42. Tsai-Goodman B, Geva T, Odegard KC, Sena LM, Powell AJ. Clinical role, accuracy, and technical aspects of cardiovascular magnetic resonance imaging in infants. Am J Cardiol 2004;94:69-74.

43. Kirchin MA, Pirovano G, Venetianer C, Spinazzi A. Safety assessment of gadobenate dimeglumine (MultiHance): extended clinical experience from phase I studies to post-marketing surveillance. J Magn Reson Imaging 2001;14:281-294.

44. Shellock FG, Parker JR, Venetianer C, Pirovano G, Spinazzi A. Safety of dimeglumine (MultiHance). Summary of findings from clinical studies and postmarketing surveillance. Invest Radiol 2006;41:500-509.

45. Kubik-Huch RA, Gottstein-Aalame NM, Frenzel T, et al. Gadopentetate dimeglumine extraction into human breast milk during lactation. Radiology 2000;216:555-558.

46. Schmiedl U, Maravilla KR, Gerlach R, Dowling CA. Excretion of gadopentetate dimeglumine in human breast milk. AJR Am J Roentgenol.1990;154:1305-1306.

47. Rofsky NM, Weinreb JC, Litt AW. Quantitative analysis of gadopentetate dimeglumine excreted in breast milk. J Magn Reson Imaging 1993;3:131-132. 
48. Chen MM, Coakley FV, Kaimal A, Laros RK Jr. Guidelines for computer tomography and magnetic resonance imaging use druing pregnancy and lactation. Obstet Gynecol 2008;112:333-340.

49. Hylton NM. Suspension of breast-feeding following gadopentetate dimeglumine administration [editorial)] Radiology 2000;216: 325-326.

50. Colosimo C, Demaerel P, Tortori-Donati P, et al. Comparison of gadobenate dimeglumine (Gd-BOPTA) with gadopentetate dimeglumine (Gd-DTPA) for enhanced MR imaging of brain and spine tumours in children. Pediatr Radiol 2005;35:501-510.

51. Hahn G, Sorge I, Gruhn B, et al. Pharmacokinetics and safety of gadobutrol-enhanced magnetic resonance imaging in pediatric patients. Invest Radiol 2009;44:776-783.

52. Dillman JR, Ellis JH, Cohan RH, Strouse PJ, Jan SC. Frequency and severity of acute allergic-like reactions to gadolinium-containing i.v. contrast media in children. AJR Am J Roentgenol 2007;189:1535-1538.

53. Bellin MF, Van Der Molen AJ. Extracellular gadolinium-based contrast media: an overview. Eur J Radiol 2008;66:160-167.

54. Eldevik OP, Brunberg JA. Gadopentetate dimeglumine-enhanced MR of the brain: clinical utility and safety in patients younger than two years of age. AJNR Am J Neuroradiol 1994;15:1001-1008.

55. Malviya S, Voepel-Lewis T, Eldevik P, et al. Sedation and general anaesthesia in children undergoing MRI and CT: adverse effects and outcomes. Br J Anaesth 2000;84:743-748.

56. Mayr M, Burkhalter F, Bongartz G. Nephrogenic systemic fibrosis: clinical spectrum of disease. J Magn Reson Imaging 2009;30 1289-1297.

57. Bhave G, Lewis JB, Chang SS. Association of gadolinium based magnetic resonance imaging contrast agents and nephrogenic systemic fibrosis. J Urol 2008;180:830-835; discussion 835.

58. Shabana WM, Cohan RH, Ellis JH, et al. Nephrogenic systemic fibrosis: a report of 29 cases. AJR Am J Roentgenol 2008;190: 736-741.
59. Wiginton CD, Kelly B, Oto A, et al. Gadolinium-based contrast exposure, nephrogenic systemic fibrosis, and gadolinium detection in tissue. AJR Am J Roentgenol 2008;190:1060-1068.

60. Chrysochou C, Buckley DL, Dark P, Cowie A, Kalra PA. Gadoliniumenhanced magnetic resonance imaging for renovascular disease and nephrogenic systemic fibrosis: critical review of the literature and UK experience. J Magn Reson Imaging 2009;29:887-894.

61. Perez-Rodriguez J, Lai S, Ehst BD, Fine DM, Bluemke DA. Nephrogenic systemic fibrosis: incidence, associations, and effect of risk factor assessment-report of 33 cases. Radiology 2009;250: 371-377.

62. Shellock FG, Spinazzi A. MRI Safety update 2008: Part 1, MRI contrast agents and nephrogenic systemic fibrosis. AJR Am J Roentgenol 2008;191:1129-1139.

63. Karcaaltincaba M, Oguz B, Haliloglu M. Current status of contrast-induced nephropathy and nephrogenic systemic fibrosis in children. Pediatr Radiol 2009;39(Suppl 3):S382-S384.

64. Thomsen HS, Marckmann P. Extracellular Gd-CA: differences in prevalence of NSF. Eur J Radiol 2008;66:180-183.

65. Halvorsen RA. Which study when? Iodinated contrast enhanced CT versus gadolinium-enhanced MR imaging. Radiology 2008; 249:9-15.

66. Weinreb JC. Which study when? Is gadolinium-enhanced MR imaging safer than iodine-enhanced CT? Radiology 2008;249:3-8.

67. Foss C, Smith JK, Ortiz L, Hanevold C, Davis L. Gadoliniumassociated nephrogenic systemic fibrosis in a 9-year-old boy. Pediatr Dermatol 2009;26:579-582.

68. Jain SM, Wesson S, Hassanein A, et al. Nephrogenic fibrosing dermopathy in pediatric patients. Pediatr Nephrol 2004;19:467-470.

69. Dharnidharka VR, Wesson SK, Fennell RS. Gadolinium and nephrogenic fibrosing dermopathy in pediatric patients. Pediatr Nephrol 2007;22:1395.

70. Penfield JG. Nephrogenic systemic fibrosis and the use of gadolinium-based contrast agents. Pediatr Nephrol 2008;23:2121-2129. 